\title{
Development of software control tools for power systems of mining and metallurgical regions
}

\author{
Vladimir Morkun, and Igor Kotov \\ Kryvyi Rih National University, 11 Vitalii Matusevych Str., Kryvyi Rih, 50027, Ukraine
}

\begin{abstract}
There are presented results of developing a conceptual trigger chart of the functioning mechanism of the decision support system. The suggested model of visualizing algorithms as a trigger net of states of the computer decision support system provides for interaction of power objects of mining and metallurgical complexes and regions. The authors introduce new interpretation of components of the network trigger model. The model is interactively connected with both the user-operator's actions and states of power system components. With that, the state of the automatic model is associated with realizing a set of metarules to control the logic output. The authors elaborate a new formalism of representing algorithms of controlling knowledgebases interacting with the outer environment which aggregates primitives of conditions, triggers and transactions of operations and greatly generalizes standard languages of algorithm visualization. It enhances elaboration of standardized smart systems interacting with the external environment. This allows description of functioning algorithms of knowledgebases and the event-driven output to ensure development of reliable standardized smart systems interacting with control objects of power systems in mining and metallurgical regions.
\end{abstract}

\section{Introduction}

Advancement of mining and metallurgical complexes and regions is integrally characterized by significant irregularity and effects of some current crisis factors [1,2]. These circumstances call for new approaches to improving efficiency of mining and metallurgical complexes in terms of assessing parameters that define their functioning. As a result, there are developed various transient-free mathematical models and tools of engineering data processing $[3,4]$.

Large-scale industrial systems of the economy including electric grids of mining regions and metallurgical enterprises are specified by considerable damages associated with emergencies and accidents. In accident elimination, a so-called "human factor" is gaining significance with intensified requirements to managerial personnel. The personnel are under great psychological and physiological pressure in a compressed time frame suffering from high material and social responsibility for their actions. Due to this, managerial personnel are often unable to provide adequate reaction to an emergency and reduce its consequences efficiently [5, $6]$.

Present-day power system as an integral part of mining and metallurgical complexes is a complicated hierarchical control object characterized by simultaneous power generation, distribution and consumption. With this in mind, the computerized smart support of the managerial operating dispatch personnel's (ODP) decisions is becoming especially urgent. Decision support systems (DSS) are integrated into operating informationcontrol complexes (OICC) of the automated Supervisory Control and Data Acquisition System (SCADA) [7].

Reliability and efficiency of dispatchers' operation is the factor involving reserves to reduce damages caused by accidents and unserved power. Identification of losses and damages in the power system is a complicated and ambiguous task comprising both reliability of power system components and that of dispatch personnel. Basic modern approaches to specifying accident (emergency, crisis) losses resulting from unserved power were analyzed. In general, there are direct losses/damages (lost resources due to breakdowns and accident elimination costs) and lost profits (income deficiency).

\section{Problem analysis}

Damages can be evaluated by using the following approaches:

- simulation of shutdown scenarios;

- methods of direct analytical calculation;

- market methods (readiness to pay for increased reliability);

- consumers' surveys;

- statistical methods.

To obtain multiple estimates of damages, reliability indices of the power consumption system and management. Meanwhile, specific damage from unserved power can be treated as tripled power costs.

The damage value for a customer is affected by the following parameters: 
- the shutdown period;

- the suddenness rate of power interruption;

- depth of limited load;

- the shutdown moment.

Thus, reliability of power supply is a probabilistic index conditioned by a number of the power system's properties.

Analysis of the damage structure and essence in power systems reveals that damage can be reduced due to enhanced automation of emergency management. A decision maker is ODP of power systems [8]. Let us specify the role of dispatch personnel in reducing accident-related damages in power systems. Here, the rate of managerial decision making should correspond to that of accident development. Yet, the decision maker is unable to react in compliance with the set rate of an emergency. Main reasons for that include a great amount of data that require faultless evaluation in the shortest time possible and psychological pressure because of increased responsibility.

Note the generalized information model of technological process management. The model is universal and can be considered invariant in terms of a professional specificity of an enterprise. The given model realizes a cybernetic approach and combines a control object's input and output data with those of a subject. Let us introduce the following symbols: $\Delta t_{1}$ is the period of the information flow passing along the first information arc; $\Delta t_{2}$ is the period of the information flow passing along the second information arc; $\Delta t$ decision maker is the period of personnel's decision making; $\Delta t_{L}$ is the total time period of the information cycle; $S_{1}$ is the control object's state at the moment $t_{1} ; S_{2}$ is the control object's state at the moment $t_{2} ; t_{1}$ is the moment of the beginning of collecting data on the control object; $t_{2}$ is the moment of complete realization of the controlling action on the control object by the control subject.

Thus, we obtain

$$
\begin{aligned}
& S_{1}=S\left(t_{1}\right), \\
& S_{2}=S\left(t_{2}\right) .
\end{aligned}
$$

With that,

$$
\Delta t_{u}=\Delta t_{1}+\Delta t_{Л \Pi P}+\Delta t_{2}
$$

From (2) it follows that

$$
t_{2}=t_{1}+\Delta t_{u}=\Delta t_{1}+\Delta t_{Л \Pi P}+\Delta t_{2} .
$$

For any professional management environment, it is true that

$$
t_{1} \neq 0, \Delta t_{\text {ЛПР }} \neq 0, t_{2} \neq 0, \Delta t_{u} \neq 0 .
$$

Then

$$
t_{2} \neq t_{1}, S_{2} \neq S_{1} \text {. }
$$

From (5) provides an important conclusion on the paradox of control: any control is based on the knowledge of an object being in the state $S_{1}$ and is realized some time later in relation to another object being in the state $S_{2}$. That is why, any control is characterized by some degree of incompleteness, unreliability and ambiguity.

The obvious solution of the control problem is

$$
\min \Delta t_{u}(X)
$$

where $\Delta t_{u}(X)$ - is the time period of the control cycle as a function of multiple control factors $X=\left\{x_{i} \mid i=1, n\right\}$.

As managerial activity is mostly of information-based and cognitive character and the control cycle is based on processing and generation of information flows, solution of problem (6) is related to the IT field. The solution is based on inclusion of the information system into the control cycle. The information system acts as an information 'pump' increasing the speed and volumes of information flows in direct and reverse arcs of the control cycle. The information system nucleus is the data base management system (DBMS), which accumulates and processes information massifs. Application of the DBMS has a considerable time gain, thus enhancing reliability of managerial decisions.

However, reduction of losses calls for new levels of control/management quality. That is why, the information system is complimented with two information mechanisms - the automated process control system (APCS) and the DSS. The APCS is a set of hard- and software modules that ensure production processes. These modules are connected with industrial equipment and their speed of operation cannot be additionally increased to a great extent. On the other hand, expert systems of managerial decision support are predominantly software complexes and are solely associated with the ODP's information activity. Consequently, it is the DSS that is noted for maximum freedom, flexibility, scalability and adaptability in changeable conditions of power system functioning. That is why, the time period for decisionmaking can be greatly reduced.

Thus, it can be concluded that on the present-day development stage of hard- and software tools of realizing managerial activity in production, reduction of time for managerial decision making $\left(\Delta t_{\text {decision maker }}\right)$ is one of the key factors of improving reliability of management and control. Conclusions like that are confirmed by numerous practitioners. This conclusion is gaining more topicality when being applied to managing power systems in emergency and crisis situations under time deficiency. For this reason, within the framework of the given problem, we should consider the issue of the automated dispatcher control system (ADCS) intellectualization.

\section{Automation tools of emergency control over power system modes}

Let us consider current scientific and practical solutions to automation of emergency control over power system modes. Emergency control of power systems is based on basic principles of emergency control applied to the professional field of power system functioning. Emergency control systems should prevent accidents and provide input of the system parameters into the area of accessible schedule values in the shortest time possible. 
Functioning of the control system under the emergency (crisis) mode differs in the fact that emergencies occur unexpectedly and develop fast. Control schedules for stationary modes become inadequate. That is why, emergency control systems should be structurally and functionally different from those in stationary (standard) modes. Comparison of the two system types are in Table 1.

Table 1. Comparison of the control systems.

\begin{tabular}{|c|c|}
\hline $\begin{array}{c}\text { Conventional control } \\
\text { systems }\end{array}$ & Emergency control systems \\
\hline $\begin{array}{l}\text { Constant functioning } \\
\text { mode }\end{array}$ & Various functioning modes \\
\hline $\begin{array}{l}\text { Inflexible structure and } \\
\text { clear distribution of } \\
\text { functions for a long } \\
\text { period }\end{array}$ & $\begin{array}{l}\text { No inflexible structure and clear } \\
\text { distribution of functions for a long } \\
\text { period, flexibility }\end{array}$ \\
\hline $\begin{array}{ll}\text { Narrow functional } \\
\text { orientation }\end{array}$ & $\begin{array}{l}\text { Wide and partially unpredictable } \\
\text { application area }\end{array}$ \\
\hline Monostructure & Polystructures \\
\hline $\begin{array}{l}\text { Regulated information } \\
\text { flows }\end{array}$ & $\begin{array}{l}\text { Dependency of information flows on a } \\
\text { situation }\end{array}$ \\
\hline Accurate information & Unreliable information \\
\hline Excessive information & Insufficient information \\
\hline Low rate of changes & High rate of changes \\
\hline $\begin{array}{ll}\begin{array}{l}\text { Predictability } \\
\text { situations }\end{array} & \text { of } \\
\end{array}$ & $\begin{array}{l}\text { Unpredictabilityy of situations, past } \\
\text { practice orientation, as a rule without } \\
\text { any sense }\end{array}$ \\
\hline $\begin{array}{l}\text { Unanimity of duties } \\
\text { and responsibility }\end{array}$ & $\begin{array}{l}\text { Combination of undivided authority, } \\
\text { distributed duties and responsibility }\end{array}$ \\
\hline Functional potential & Managerial potential \\
\hline $\begin{array}{l}\text { Predominance of social } \\
\text { and economic goals } \\
\text { and functional criteria }\end{array}$ & $\begin{array}{l}\text { The goal is effciency of elimination of } \\
\text { accidents and their consequences; the } \\
\text { criteria are reduction of time for goal } \\
\text { achivement, minimal losses (victims) }\end{array}$ \\
\hline
\end{tabular}

ODP as a tool of operative dispatch emergency control can be considered as both 'a week link' of the ADCS and a reserve for increasing efficiency of power system management/control in emergencies.

It is evident that the nucleus of the ADCS is the operating information complex (OIC). The OIC is mostly used for standard modes with such functions as state assessment, reliability analysis and improvement of flowdistribution, which enhance reliable functioning of the power system. The pattern changes greatly if the OIC is to function under unpredictable circumstances or in case of emergencies in any important components of the power system. In these cases, the OIC acts predominantly as a system of data collection and transmission. Complicated applied software created for standard modes can be of no use here. In these conditions, it is mostly dispatch personnel's responsibility to make decisions about eliminating an accident. The ODP faces the problem of analytical processing of large volumes of operative data which are characterized by considerable incompleteness or unreliability and have to make responsible decisions under severe time constraints. Managerial decision making is difficult to structure and formalize. Correct and efficient decisions are dependent on a dispatcher's work experience, his/her ability to adequately react to unpredictable stressful situations and psychophysiological characteristics.
In [9], Budovskyi indicates that 'in each individual case, technological failures are treated as suddenness that makes personnel face a number of various problems. In this case, especially on the initial stage of disturbance when the personnel are not ready to act and the emergency requires taking urgent steps, they are inevitably subject to emotional tension. Here, the personnel's clear and correct actions are possible only in case of their high-quality readiness to work under given circumstances'. It is evident that there is a problem of improving the ODP's quality and reliability as responsible part of the ADCS. The problem is solved in many fields including engineering psychology, situational software management, automated knowledge assessment, etc. To improve the ODP's reliability, there are used multiple methods and approaches: situation evaluation trees, flowcharts and action plans, algorithmization of operative switching plans, observation maps, the business game theory, methods of deduction and expert systems.

The conducted analysis indicates that all the mentioned methods are quite effective and their application enhances reliability of dispatch personnel to some degree. Further increase of the ODP's reliability is associated with application of training ICT and knowledge assessment - switching training simulators (STSs).

Application of STSs enables a dispatcher to acquire experience of solving operating control problems under standard and emergency modes of power systems. While building the STS, the results of analyzing a dispatcher's breakdowns (errors) are required to be used. There are two types of dispatchers' breakdowns - regular and random. Regular breakdowns are those occurring due to dispatchers' forgetfulness or lack of knowledge as to corresponding sections of normative, directive materials. Random breakdowns are those caused by dispatchers' mistakes, misses and errors.

To reduce the number of regular breakdowns, the methods of increasing and maintaining personnel's technical knowledge are used including lectures and exams aimed to provide knowledge and skills of applying the content of normative and technical documents. To reduce the number of random breakdowns, there are used specific instructions, interviews and emergency trainings aimed at increasing personnel's attention span and accurate responses.

As is mentioned, optimization of obtained knowledge and skills as well as control over the results are provided by simulators including the STSs. The most general features of simulators include:

- a mimic of an electric grid or a substation with indicated symbols and location of commutation equipment;

- simulation of bodies controlling commutation equipment and control indicators for correct accomplishment of operations;

- a logical control block aimed to conduct training according to one or more 'inflexible' programmed scenarios - a set of sequences of operations required for a given problem or a given grid.

To acquire required skills for maintaining parameters of the power system mode in a given field under standard 
and emergency modes associated with sudden imbalances of active power and changes in the grid scheme, there are used mode simulators. They are actively applied to largescale national power associations and companies of the USA, Canada, Western Europe, Russia and Japan. The mode simulator can be realized on:

- one of the OIC computers removed from the online mode during the training period;

- a computer intended for personnel's training.

In the $1990 \mathrm{~s}, T E-2 M$ was the most advanced simulator with both relatively simple and complex switching under standard modes with various (standard) schemes of substations as well as problems for dispatchers' independent actions to eliminate accidents. In subsequent years, universal programmed simulators have become popular including Modus and TWR-12. The simulators include a powerful graphic subsystem which enables reflection of electric grids of limitless sizes with the option of selecting a scheme in the given window. The schemes can be divided into functional blocks comprising separate parts and be united into multilevel hierarchical schemes. Under the supervision of Lyubarskyi, the simulator of the smart grid model OPTIMAS was created with multiple applications. The universal mode simulator FENIKS (Russia) is worth mentioning as it is widely used by dispatch departments and services of power associations. There are some other simulators used: RETREN (Russia), Finist (Russia), KOMPAS-ASDU (Russia), EPRI OTS (the USA), FAST DTS (the EU), and $P O R T$ (Ukraine). Fig 1 contains examples of technical training systems and simulators.

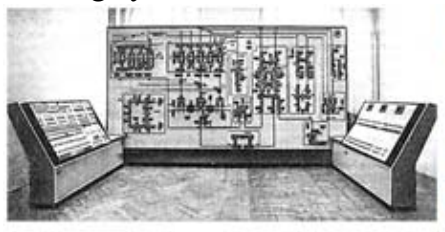

a)

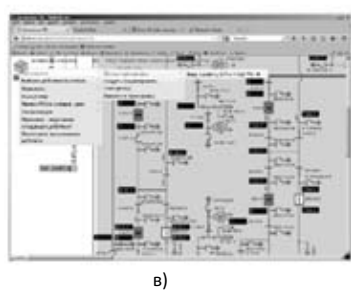

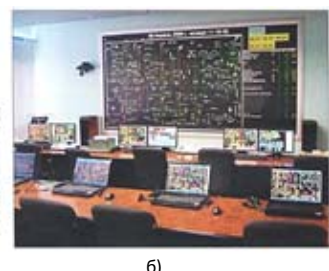

а) Тренажер диспетчерського щита для оперативного персоналу електричних мереж

б) Режимний тренажер финист оду югА в) пОРТ - тренажер ліквідації системних аварій a) The dispatch board simulator for electric grid personnel

b) The mode simulator FINIST of the ODC

c) The accident elimination simulator PORT

Fig. 1. Examples of training systems and the stimulator.

The given analysis reveals that simulators allow increasing efficiency of emergency prevention in power systems. However, current statistics of the human factor impacts represents that $20-25 \%$ of all violations of block equipment modes and $30 \%$ of all failures in power engineering are caused by personnel's errors. About $90 \%$ of those committing a violation had good professional knowledge [10]. Considering the fact that human psychophysiological features have natural constraints to stress resistance, reaction extent, accuracy of big data processing with lack of time, it should be concluded that simulators are to be considered as an intermediate tool for limited improvement of the ODP efficiency. Smart DSSs are higher-level tools with greater reserves of growing efficiency of controlling power systems, i.e. intellectualization tools for power systems.

The research looks into the urgent problem of automatizing control over power grid modes by using software controllers of professional knowledge levels initiated by triggers of the controlled object.

Modern electric grids create a series of specific requirements both to the smart grid itself and to methods of designing it. Let us enumerate some basic requirements: simultaneous functioning with declarative and procedure forms of knowledge representation, identical functioning of the system under the modes of logical input in the knowledgebase and processing of the database, provision of the practical hardware interface with components of power objects and the automated dispatcher control system, implementation of the user visual interface with operating dispatch personnel (ODP), efficient translation into internal system codes and interpretation of controlling meta-rules, realization of the software mechanism of the inductive inference as transactions of meta-rules. The formulated requirements condition the necessity of a new exclusive approach to representing and visualizing structural and functional models of the software complex of the decision-support system (DSS). The model can be applied to solving the following problems: providing identical representation of algorithms of the DSS functioning and algorithms of knowledgebase translation and processing at all representation levels, actual fulfillment of the programme depending on parameters (signals) of conditions of the external surrounding of the smart system.

The research aims to investigate into new formalism of representing control algorithms of knowledgebases interacting with the external environment that aggregates primitives of states, triggers and transactions of operations and generalizes standard languages of algorithm visualization. Each formalism possesses both advantages and disadvantages as well as its preferential application fields. Analysis of their constraints is essential here.

\section{Analysis of algorithm representation forms}

The formal language of algorithm flowcharts is standardized and well tested. In most cases, based on a designer's talent, a problem can be reduced to visualizing the flowchart of an algorithm.

Dijkstra's flowcharts determine a certain alternative approach to visual modelling of algorithms [11]. Dijkstra introduced principles of structuring flowcharts, i.e. the topology constraint principle, the principle of vertical orientation of inputs and outputs, the single vertical principle, the principle of stringing typical flowcharts into a single vertical.

In order to 'consolidate' algorithm flowcharts and extinguish their complexity, the Nassi-Shneiderman method of visualization is suggested [12]. It ensures absolute observance of structured programming 
principles and top-down refinement of a problem without binding arrows.

The well-known transient graph is a graphical representation of the machine model. Automation formalisms are expressed by Mealy and Moore machines. Analysis of researches allows admitting the following models in formalizing algorithms - absence of a state hierarchy, generalization of transients.

The SWITCH-technology of designing and Harel's state charts are used as some solutions to the mentioned problems. The SWITCH-technology is based on representation of a programme as a hierarchy of interacting machines. The model enables recording external events.

R-charts are a technology of visualizing system design developed and applied in the Cybernetics Institute of the Academy of Sciences of Ukraine under the supervision of V.M. Hlushkov. Adoption of the standard indicates efficiency of the applied R-charts..

The L-network formalism suggested by M.F. Lekarev is an original solution in the field of modelling computing processes [13].

\section{The state flowchart of the trigger DSS}

The software current state triggers identify mode parameters at the input and generalize situational codes at the output. This state is associated with a transaction, the fulfillment of which implements operations related to the knowledgebase. Depending on the result of the transaction, the DSS proceeds to another state.

Fig. 2 contains a developed generalized flowchart of the DSS states based on transactions of meta-rules.

$$
\begin{gathered}
S=<Q, q_{0}, F, T, P>, \\
S=<s_{i} \mid s_{i}=<q_{i}, t_{i}, p_{i}>, q_{i} \in Q \vee q_{i} \in F \vee q_{i}=q_{0}>.
\end{gathered}
$$

The flowchart conjugates with the chart of data interaction of the DSS with the external environment through hard- and software tools of the automatized dispatcher control system of the electric grid.

Let us introduce interpretation of components of the trigger state grid of the DSS. The series of operation positions (states) of the network is

The series of the network transients is

$$
\Delta \Sigma=\Delta \cup \Delta_{t}=\left\{\delta_{i} \in \Delta \vee \delta_{i} \in \Delta_{i}\right\},
$$

where $\Delta_{\Sigma}$ is a total series of network transients; $\Delta$ is a series of transients between the network states; $\Delta_{t}$ is a series of trigger transients of the network.

The series of the input functions is

$$
\begin{gathered}
I(S): S \rightarrow<Q_{-1}, V_{\Sigma} \cup W_{\Sigma}>, \\
I\left(s_{i}\right): s_{i} \rightarrow\left\{q_{i-1}, v_{i-1} \cup w_{i-1}\right\},
\end{gathered}
$$

where $Q_{-1}$ is a series of previous states as to the current state.

The series of output functions is

$$
a: S \rightarrow s_{a} \text {. }
$$

Thus, we reduce the machine trigger model to the operational trigger network of states

In the most general form, the example of model (11)

$$
N_{s}=<S, \Delta \Sigma, I(S), O(S)>.
$$

can be presented by the following graphical interpretation given in Fig. 3.

In the suggested model, a state is a block of a trigger, an operational transaction, and a result of calculations and output symbols (codes). We denote the state by a vertical line with the state indicator above. Depending on the obtained input codes, the network functioning becomes a branching process as a transient to the next state starts. If the state possesses more than one output, only one transient is chosen. Observance of the given condition guarantees unambiguity and determination of the performed algorithm. The operating cycle of the network is activity of a current state.

The presented considerations enable introducing the notion and the function of marking for the developed model of the operational state network. The presented considerations enable introducing the notion and the function of marking the operational state network for the developed model. The marking function in its essence is an activation function and it realizes choice of an active state out of a whole series of network states

$$
\text { a: } S \rightarrow s_{a},
$$

where $\#\left(s_{a}\right)=1 \mid s_{a} \in S$ is the only active state under the given cycle. The rest of the states are non-active $-\#\left(s_{i}\right)=$ $0 \mid \forall s_{i} \in S \wedge s_{i} \neq s_{a}$.

The marked state network will look like

$$
N_{s}=<S, \Delta_{\Sigma}, I(S), O(S), a>.
$$

On the basis of the developed state model, one can formulate a general principle of the network implementation. The network implementation (the course of implementing the computing algorithm of the software system) is determined by transients between states or state activation and denotes a step-by-step re-marking along some path on the state graph.

\section{Algorithm implementation on the trigger state network}

By solving the problem on the state network of the software system, we implement an algorithm expressed by a path on the transient graph. According to the structuring theory, the algorithm scheme can be reduced to a basis set of structures - a consequent cycle, branches and backouts (cycles). The trigger state model enables these principles.

The example of a fulfilled algorithm along the state path $s 0 \rightarrow s 2 \rightarrow s n q \rightarrow s 0$ of the considered network is reflected by the cycles presented in Fig.4. The trigger $t_{0}$ initiates the procedure.

Models enable specifying the model of a state depicted in Fig. 5. 
We should consider the fact that the programme is a sub-set of a set of paths on the graph of the state network.

$$
P R O G=B_{\text {prog }}
$$

$\forall s_{i k} \forall s_{i k+1} \forall k \mid s_{i k} \in S_{i} \wedge s_{i k+1} \in S_{i} \wedge k=1,2, \ldots, n_{0}: s_{i k}<s_{i k+1}$,

$$
\begin{gathered}
B_{\text {prog }} \subseteq N_{s}, \\
B_{\text {prog }}=\left\{b_{i} \mid I=1, n_{b}\right\},
\end{gathered}
$$

$$
b_{i}=\left\{s_{i, k}, s_{i, k+1}, \ldots, s_{i, n b i}\right\},
$$

where $\mathrm{PROG}=$ Bprog is a programme (an algorithm of accomplishing a series of transactions); Bprog $=\left\{b_{i} \mid \mathbf{i}=1, n_{b}\right\}$ is a set of branches (paths) of the algorithm of accomplishing the programme; $b_{i}$ is the $\mathrm{i}$-th branch of accomplishing the algorithm of the programme set as a strict sequence of states of the trigger network; $N_{s}$ is a complete network of states.

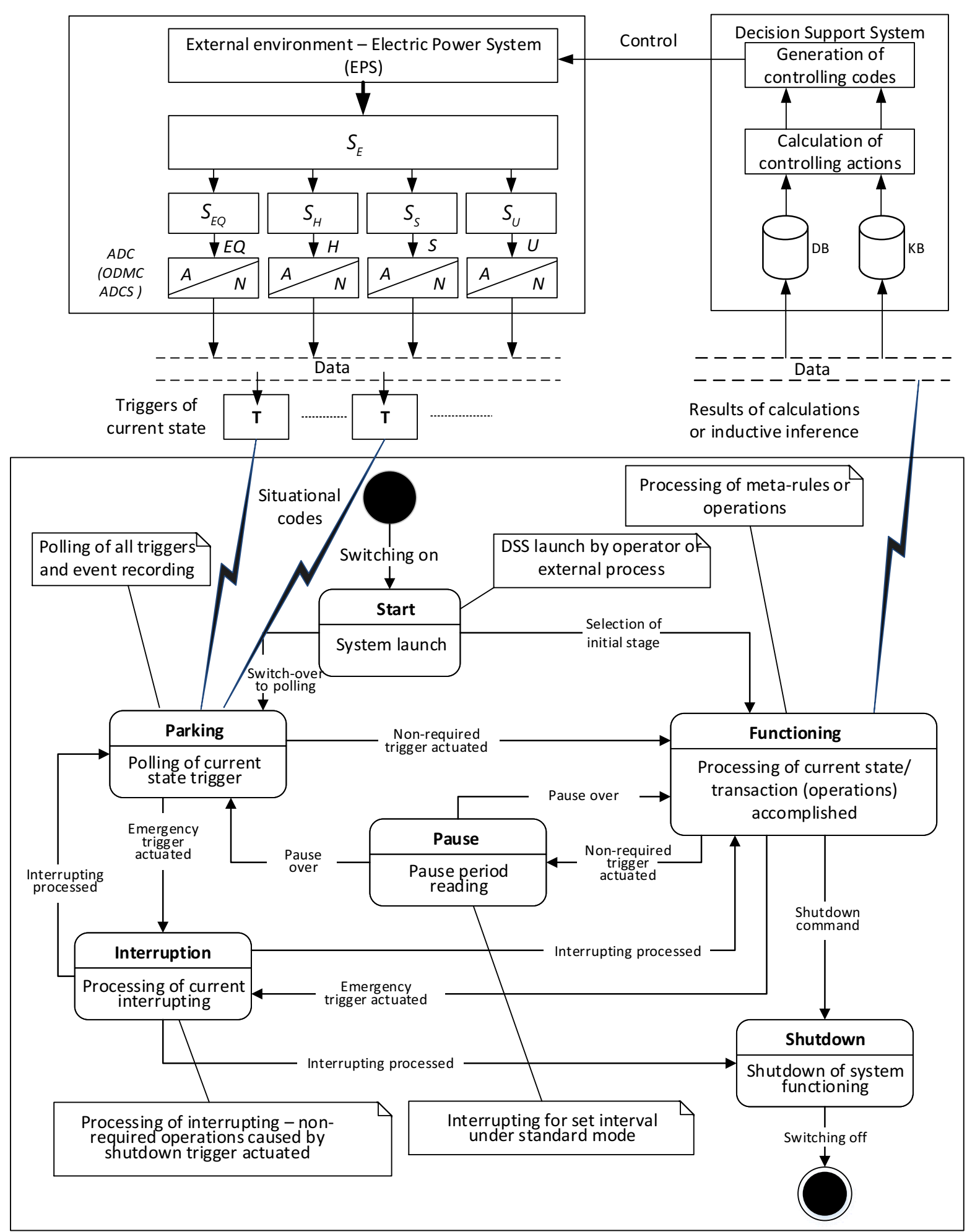

Fig 2. The state flowchart of the trigger DSS. 

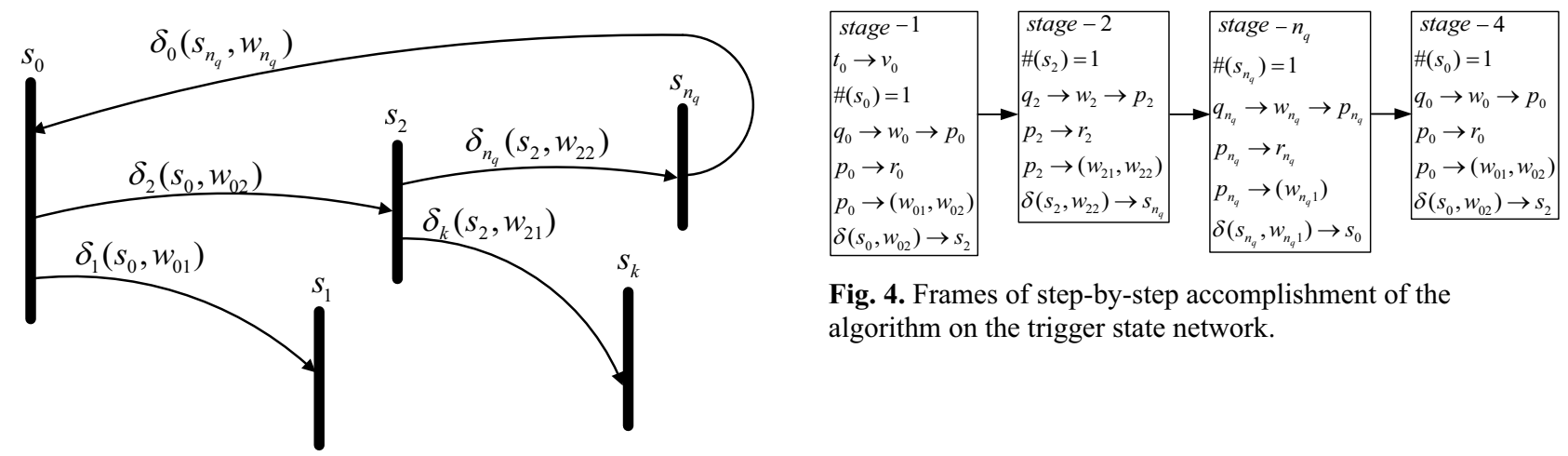

Fig. 4. Frames of step-by-step accomplishment of the algorithm on the trigger state network.

Fig. 3. The state flowchart.

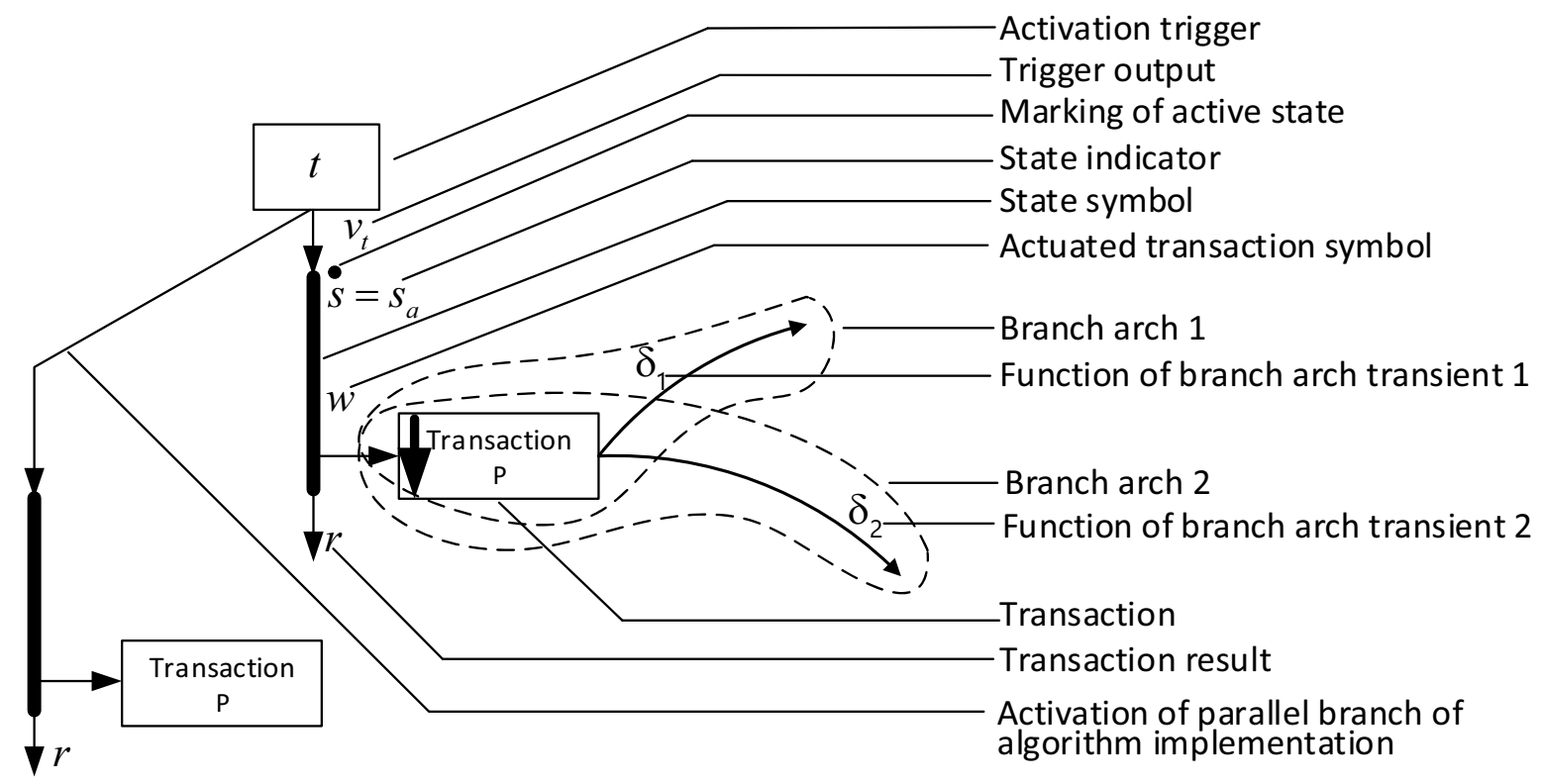

Fig. 5. A state of accomplishing the algorithm of the programme DSS system.

\section{Practical software implementation of an automated system}

Based on the obtained structural and logical models, a knowledge base was developed and the effectiveness of a professional thesaurus was evaluated.

Fig. 6 illustrates dynamics of relative efficiency of the thesauruses.

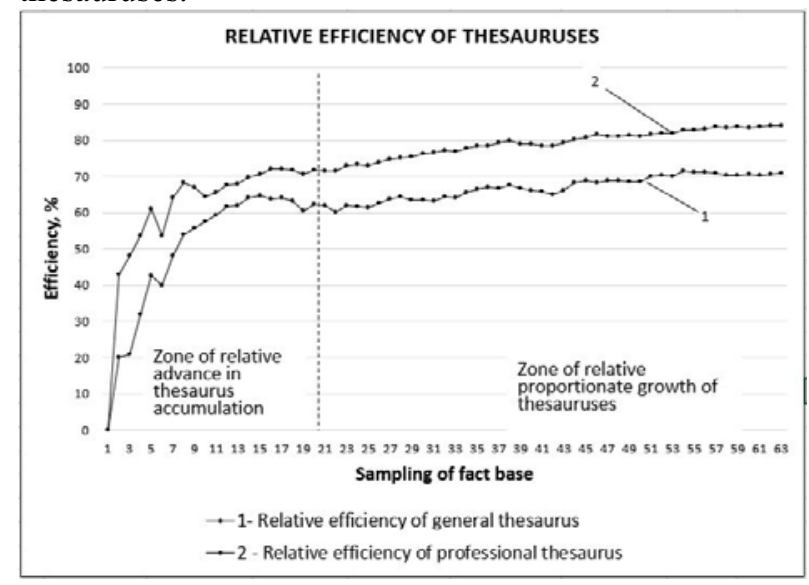

Fig. 6. Dynamics of growing relative efficiency indices of the general and specialized thesauruses.
The diagrams have two distinct zones - that of relative advance in thesaurus accumulation and that of relative proportionate growth of thesauruses. Efficiency of the specific slang and abbreviation thesaurus is higher than that of the general one. The zone of relative advance in thesaurus accumulation is characterized by accumulation of facts in a single terminological and semantic block while the thesaurus is formed rapidly and almost does not grow. The zone of relative proportionate growth of thesauruses indicates the increased volume of the linguistic corpus when new terminological and semantic blocks accumulate. In this case, the thesaurus starts growing again.

Expressions for calculating integral factors of efficiency of corresponding general and professional thesauruses of abbreviations and slang are given in the form of the formulae:

$$
\begin{aligned}
& K_{E T}=\left(1-\frac{\alpha_{T}}{\alpha_{B}}\right) \cdot 100 \%=\left(1-\frac{\operatorname{arctg}\left(a_{T}\right)}{\operatorname{arctg}\left(a_{B}\right)}\right) \cdot 100 \% ; \\
& K_{E T A}=\left(1-\frac{\alpha_{T A}}{\alpha_{B}}\right) \cdot 100 \%=\left(1-\frac{\operatorname{arctg}\left(a_{T A}\right)}{\operatorname{arctg}\left(a_{B}\right)}\right) \cdot 100 \%,
\end{aligned}
$$

where $K_{E T}$ is an efficiency factor of the general thesaurus; $K_{E T A}$ is an efficiency factor of the abbreviation and slang 
thesaurus; $\alpha_{T}$ is a slope angle of the approximated straight line for the general thesaurus; $\alpha_{T A}$ is inclination of the approximated straight line for the abbreviation and slang thesaurus; $\alpha_{B}$ is inclination of the approximated straight line for the fact base; $a_{T}$ is a factor under $V_{K B}$ in the straight line equation for the general thesaurus; $a_{T A}$ is a factor under $V_{K B}$ in the straight line equation for the abbreviations and slang thesaurus; $a_{B}$ is a factor under $V_{K B}$ in the straight line equation for the fact base.

Graphical results of approximation and explanations of calculations are given in Fig. 7.

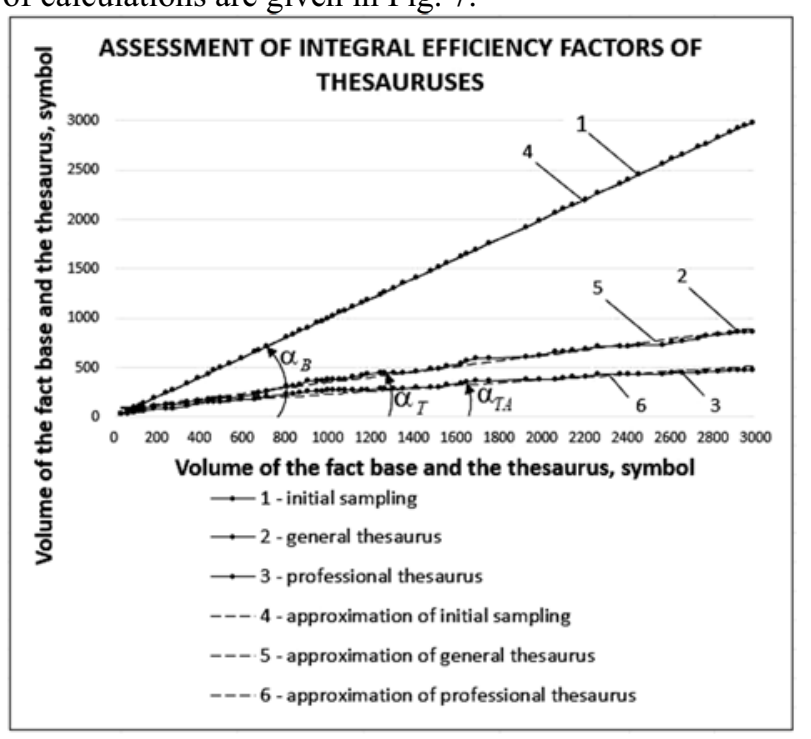

Fig. 7. Calculation of integral factors of thesaurus efficiency.

The physical meaning of the integral factor of thesaurus efficiency is a ratio of inclination of the approximated straight line of the thesaurus growth speed to the inclination of the approximated straight line of the growth speed of the initial base.

Substitution of calculated values provides the following results, $\%$ :

$$
\begin{aligned}
& K_{E T}=\left(1-\frac{\operatorname{arctg}(0,2751)}{\operatorname{arctg}(1)}\right) \cdot 100 \%=65,82 ; \\
& K_{E T A}=\left(1-\frac{\operatorname{arctg}(0,1439)}{\operatorname{arctg}(1)}\right) \cdot 100 \%=81,81 .
\end{aligned}
$$

Thus, calculations indicate that efficiency of the general thesaurus makes $65.82 \%$, while that of abbreviations and slang is $81.88 \%$. As a result, efficiency of application of knowledge bases increases when the DSS professional area is more specific. The professional area of emergency control over power system modes is highly specific and building its thesaurus is very reasonable.

After building the knowledge base and evaluating its effectiveness, the problems of connecting DSS to ADCS tools are solved. The main form of the developed software package is shown in Fig. 8.

\section{Conclusion}

There is a model of visualizing algorithms presented as a trigger network of states of a software system ensuring its interaction with the external environment. The trigger flowchart of states and event interaction of the DSS with power objects is developed. The machine model of the DSS functioning with specified semantics of states, transactions and triggers is implemented for the state flowchart. The developed model is generalized in relation to the classical machine model with an output. The model of visualizing a machine formalism as programme system states controlled by triggers is elaborated. Each state implements just one transaction of meta-rules.

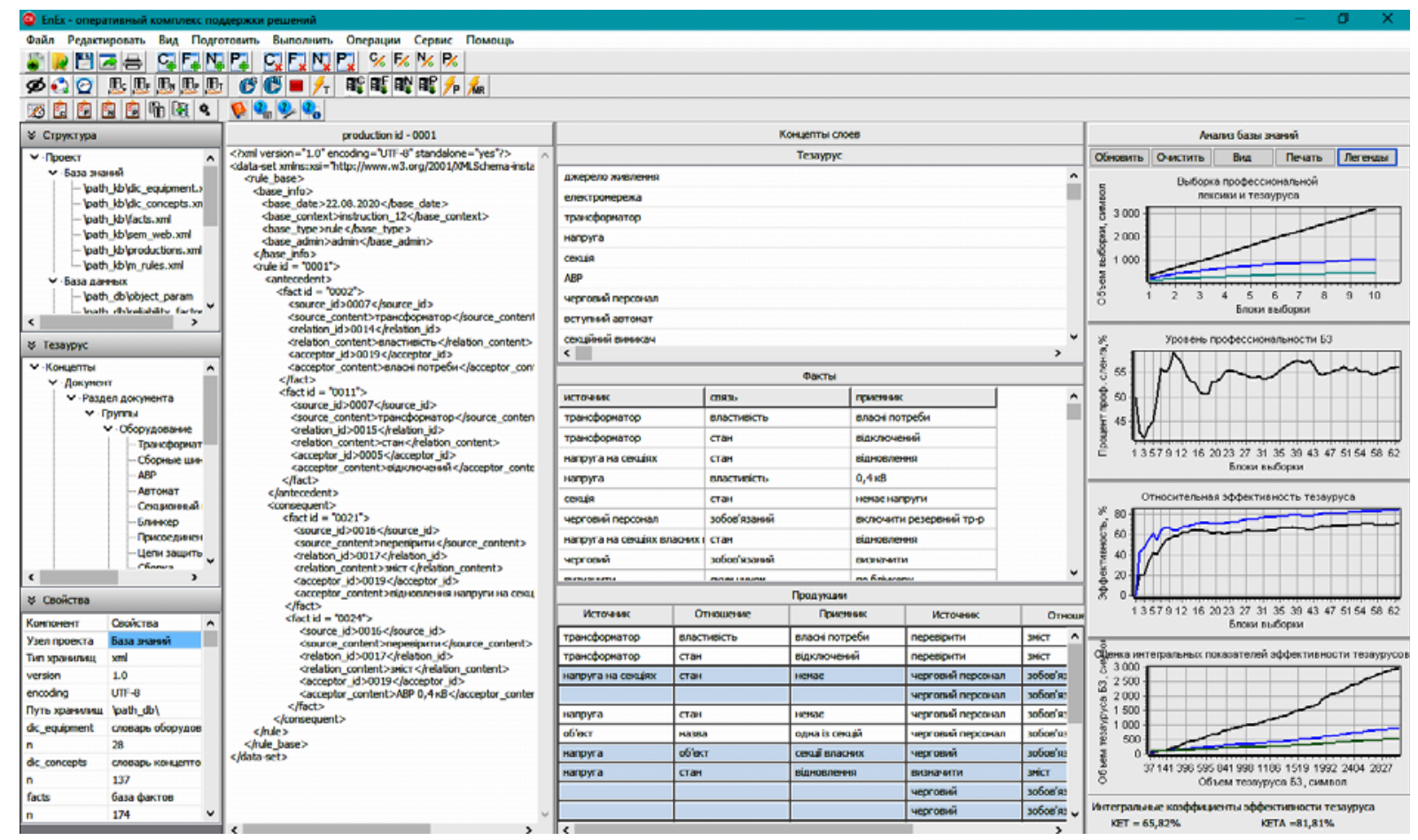

Fig. 8. The main form of the interface of the software package DSS. 
The research paper gives a developed structure and a fundamental generalized trigger flowchart of the algorithm of the DSS functioning. The suggested model of algorithm visualization presented as a trigger network of system states ensures interaction with the external environment. New interpretation of components of the trigger model is introduced.

Practical applicability, value and significance of the developed models and criteria for assessing efficiency of thesauruses are confirmed.

The assessment of the economic efficiency of the DSS in emergency modes of the power system. Metrics for assessing the quality of the DSS were developed and the quality of the developed DSS was assessed. DSS has shown advantages over analogues in terms of defining criteria. A methodology has been developed and the reliability of a dispatcher watch in emergency mode has been assessed. A quantitative assessment of the effect of increasing the reliability of the DCP from the use of the DSS in the elimination of an emergency violation of the EPS mode has been carried out. The practical increase in the reliability of the ODP from the use of the DSS in the elimination of the accident amounted to $37.2 \%$. The use of the DSS provides an increase in the maximum permissible time of continuous operation of the ODP with a reliable elimination of the accident 1.5 years.

Further research involves developing flowcharts of interpreting the knowledgebase and an inductive inference block, which are functionally overlapped unlike the classical architecture of smart systems. It is suggested to include an ontology level selector into the DSS structure in order to select a form of knowledge and data representation online as well as modules of dynamic formation, verification and ontology replenishment.

\section{References}

1. Z.M. Khasheva, L.P. Shulgaty, V.I. Golik, Yu.I. Razorenov, K.G. Karginov, About the equivalence of ore deposit development indicators. International Business Management 10(20), 4868-4872 (2016)

2. P. Manish, M.K. Bhaskar, Review of Power System Blackout. International Journal of Research and Innovation in Applied Science 3(VI), 8-13 (2018)

3. V. Morkun, N. Morkun, A. Pikilnyak, The adaptive control for intensity of ultrasonic influence on iron ore pulp. Metallurgical and Mining Industry 6(6), 8$11(2014)$

4. V. Morkun, N. Morkun, V. Tron, Distributed control of ore beneficiation interrelated processes under parametric uncertainty. Metallurgical and Mining Industry 7(8), 18-21 (2015)

5. Md. M. Abrar, Power cut off and Power Blackout in India a Major threat: An Overview. International Journal of Advancements in Research \& Technology 5(7), 8-15 (2016)

6. H.H. Alhelou, M.E. Hamedani-Golshan, T.C. Njenda, P.A. Siano, Survey on Power System Blackout and Cascading Events: Research Motivations and Challenges. Energies 12, 1-28 (2019)
7. S. Khairy, H.A. Gabbar, SCADA and Smart Energy Grid Control Automation, in Smart Energy Grid Engineering (2017), pp. 481-510

8. D.A. Panasetskiy, N.V. Tomin, V.G. Kurbatskiy, N.I. Voropay, D.N. Efimov, Intelligent emergency control of power system modes, in XII All-Russian Meeting on Management Problems, Institute of Management Problems named V.A. Trapeznikov, RAS, 2014, pp. 4770-4782

9. V.P. Budovsky, Ensuring reliable operation of operators of the subjects of operational dispatch control in case of emergency situations in the power system. Operational management in the electric power industry 4, 11-26 (2006)

10. V.T. Voronin, Mode simulators as a means of ensuring the reliable work of operating personnel, in Operational management in the electric power industry (Panorama, Moscow, 2005), p. 39-45

11. O.-J. Dahl, E.W. Dijkstra, C.A.R. Hoare, Structured Programming (Academic Press, London and New York, 1972)

12. I. Nassi, B. Shneiderman, Flowchart Techniques for Structured Programming. SIGPLAN Notices of the ACM 8(8), 12-26 (1973)

13. M.F. Lekarev, The graphic process of software development for logically complex applications. Technical reports from the university of applied sciences Hamburg, 25, 36-38 (1993) 